\title{
Fast and large-area fabrication of plasmonic reflection color filters by achromatic
} Talbot lithography

Wu, Qingjun; Xia, Huijuan; Jia, Hao; Wang, Hao; Jiang, Cheng; Wang, Liansheng; Zhao, Jun; Tai, Renzhong; Xiao, Sanshui; Zhang, Dongxian

Total number of authors:

12

Published in:

Optics Letters

Link to article, DOI:

10.1364/OL.44.001031

Publication date:

2019

Document Version

Peer reviewed version

Link back to DTU Orbit

Citation (APA):

Wu, Q., Xia, H., Jia, H., Wang, H., Jiang, C., Wang, L., Zhao, J., Tai, R., Xiao, S., Zhang, D., Yang, S., \& Jiang, J. (2019). Fast and large-area fabrication of plasmonic reflection color filters by achromatic Talbot lithography. Optics Letters, 44(4), 1031-1034. https://doi.org/10.1364/OL.44.001031

\section{General rights}

Copyright and moral rights for the publications made accessible in the public portal are retained by the authors and/or other copyright owners and it is a condition of accessing publications that users recognise and abide by the legal requirements associated with these rights.

- Users may download and print one copy of any publication from the public portal for the purpose of private study or research.

- You may not further distribute the material or use it for any profit-making activity or commercial gain

- You may freely distribute the URL identifying the publication in the public portal 


\title{
Fast and large-area fabrication of plasmonic reflection color filters by achromatic Talbot lithography
}

\author{
Qinguun Wu ${ }^{1,3}$, HuIJUAN XIA ${ }^{2}$, HAO JIA ${ }^{1}$, HAO WANG $^{1}$, CHENG JIANG ${ }^{1}$, \\ LIANSHENG WANG ${ }^{2}$, JUN ZHAO ${ }^{2}$, RENZHONG TAI ${ }^{2}$, SANSHUI XIAO ${ }^{3}$, DONGXIAN \\ ZHANG ${ }^{1,4^{*}}$, SHUMIN YANG ${ }^{2 *}$ AND JIANZHONG JIANG ${ }^{4 *}$ \\ ${ }^{1}$ State Key Laboratory of Modern Optical Instrumentation, Zhejiang University, Hangzhou, 310027, People's Republic of China \\ ${ }^{2}$ Shanghai Institute of Applied Physics, Chinese Academy of Sciences, Shanghai, 201204, People's Republic of China \\ ${ }^{3}$ Department of Photonics Engineering, Technical University of Denmark, Kgs. Lyngby, 2800, Denmark \\ ${ }^{4}$ International Center for New-Structured Materials, State Key Laboratory of Silicon Materials and School of Materials Science and Engineering, \\ Zhejiang University, Hangzhou, 310027, People's Republic of China \\ *corresponding author: zhangdx@zju.edu.cn,yangshuimin@sinap.ac.cn, and jiangjz@zju.edu.cn
}

To overcome the limits of traditional technologies which cannot achieve high resolution and high throughput simultaneously, here we propose a novel method, i.e., achromatic Talbot lithography, to fabricate large-area nanopatterns fast and precisely. We successfully demonstrate reflection color filters with maximum size of about $0.72 \times 0.72 \mathrm{~mm}^{2}$ with a time of only 20 seconds, which have colors similar to simulations and small area devices fabricated by electron beam lithography. These results indicate the possibility of large-scale fabrication of plasmonic color filters with high resolution efficiently by the achromatic Talbot lithography method.

http://dx.doi.org/XXX

\section{Introduction}

Color filters are important components for advanced optical techniques, such as digital cameras, projectors, image sensors or other optical instruments [1,2]. The traditional color filters are based on chemical dyes or pigments, which have many obvious drawbacks, i.e., vulnerability to processing chemicals, and performance degradation with long-duration ultraviolet light or high temperature. Hence, plasmonic color filters become attractive [3-6]. The commonly used fabrication methods are electron beam lithography (EBL) and focused Ion beam (FIB) [7-15] with high accuracy. However, both fabrication processes are dot-by-dot with electron or ion beam, which are small-scale, time-consuming, and high-cost, restricting them to be potential industrial applications. Thus, development of new fabrication processes with large-area, high throughput and low cost are strongly demanded. Selfassembly or nanoimprint were used to fabricate color filters, which cannot reach high resolution and throughput at the same time $[16,17]$. Interference lithography (IL), including conventional 2beam IL [18,19]) and multiple-beam IL [20-22]), has also been put forward as an effective way to fabricate high resolution nanostructures, but, with the drawback of low light usage efficiency. We recently proposed four-beam interference lithography with high resolution, strong exposure intensity and excellent coherence as a promising technique for manufacturing nanopatterns with both high precision and throughput, but only first order diffraction light can be used in four beam lithography [22]. Besides, traditional Talbot lithography and displacement Talbot lithography are also considered as alternative ways to fabricate high resolution nanostructures, but the self-image patterns can only be obtained in a certain distance which is difficult to precisely control. [23,24].

In this work, we propose a novel method, Achromatic Talbot lithography (ATL), to achieve fast and large-area fabrication of plasmonic reflection color filters, which is based on the Talbot effect, i.e., when a plane wave is incident upon a periodic diffraction grating, the image of the grating is repeated at regular distances away from the grating plane, using the Talbot grating as a mask and the soft $x$ ray as the lithography source [25-28]. By comparing with four-beam interference lithography, ATL only uses a single grating mask. This advantage simplifies the mask fabrication process and enables to use full illuminating light to achieve higher light usage efficiency. Consequently, ATL becomes a more effective method to fabricate plasmonic color filters with high resolution and throughput.

\section{Structure and method}

Fig. 1 illustrates the scheme of the nanostructure of plasmonic reflection color filters designed here. Fig. 1a shows the side view of the nanostructure including the silicon substrate, negative photoresist - hydrogen silsesquioxane (HSQ) pillars and silver films from bottom to top. Fig. 1b shows the top view of the structure. $P$ represents the period of the periodic arrays, and the diameter of the pillar used here is the half of the period. Fig. 1c shows the threedimensional graph of the structure. 

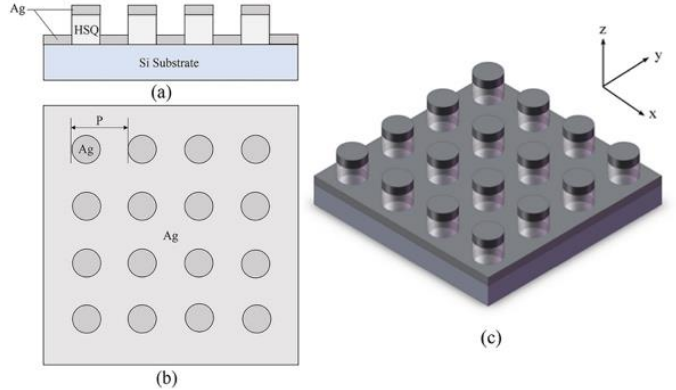

Fig. 1. (a) Illustration of the side view of the periodic nanostructures. The structure includes the silicon substrate, optical resists hydrogen silsesquioxane (HSQ) and Ag films from bottom to top. (b) Illustration of the top view of the periodic nanostructures. P represented the period of the nanostructures, the duty cycle is 0.5 . (c) The three-dimensional graph of the color filter.

The small-area color filter samples and the achromatic Talbot gratings are prepared by electron-beam lithography (EBL) systems (CRESTED CABL-9000C), in which the silver films are deposited by using electron-beam evaporation. A reflection optical microscope (Nikon 80i), a scanning electron microscope (SEM, Zeiss Ultra 55) and a self-manufactured micro-area spectral analyzer system were applied to characterize the nanostructures fabricated here. The fabrication of large area sample by using ATL is carried out at the Soft-X Ray Interference Lithography Beamline (BL08U1B) in Shanghai Synchrotron Radiation Facility (SSRF).

The nanostructures here are composed of silver nanodisks atop HSQ nanopillars and silver film. The filtering effect of the nanostructure is mainly due to the excitation of localized surface plasmon resonances (LSPR) on the nanodisks, resulting in the enhanced absorption of the resonance wavelength, and thus different colors, which has been described in our previous work [15].

Fig. 2a shows the schematic diagram of ATL When the Talbot grating with period $P^{\prime}$ is illuminated by coherent light of wavelength $\lambda$, self-images are formed at multiples of Talbot distance $\mathrm{Z}_{\mathrm{T}}$.

$$
Z_{T}=\frac{2 P^{2}}{\lambda}
$$

When a broadband incident light with a bandwidth of $\Delta \lambda$ is applied, the Talbot images smear and overlap due to different incident wavelengths at a certain distance. The smearing and overlapping of self-images will disappear and lead to achromatic and stationary patterns beyond the achromatic Talbot distance $\mathrm{Z}_{\mathrm{A}}$, the minimum mask to sample distance in ATL.

$$
Z_{A}=\frac{2 P^{2}}{\Delta \lambda}(2)
$$

The illumination wavelength used here is $13.5 \mathrm{~nm}$, and the spectral bandwidth $(\Delta \lambda / \lambda)$ is $3 \%$, so that the achromatic Talbot distance in our experiment is about $380 \mu \mathrm{m}$. For the dot diffraction grating, the resulting array pattern period is equal to $1 / \sqrt{2}$ of the mask grating period rotated $45^{\circ}$, since a new dot appears in the center of every four dots through the mask transmission [19]. However, it should be mentioned that the areas of color filter and the corresponding mask grating are the same. By comparing with the four-beam interference lithography, in which only the first order diffraction is recorded, ATL has much higher efficiency, utilizing all of the transmitted intensity of soft-X ray [20]. Figs. 2b-e show the fabrication processes of the Talbot grating. Firstly, $5 \mathrm{~nm}$ thick $\mathrm{Cr}$ and $10 \mathrm{~nm}$-thick $\mathrm{Au}$ are evaporated on the $\mathrm{Si}_{3} \mathrm{~N}_{4} / \mathrm{Si} / \mathrm{Si}_{3} \mathrm{~N}_{4}$ substrate, which are served as an adhesion layer and a seed layer, respectively. The thickness of each $\mathrm{Si}_{3} \mathrm{~N}_{4}$ layer is $100 \mathrm{~nm}$. Secondly, the photoresist pillars of the nanoarrays of the Talbot grating are exposed by using e-beam lithography. A $100 \mathrm{~nm}$-thick Au film is then electroplated as light blocking layer on the Au seed layer. Finally, the photoresist, $\mathrm{Si}_{3} \mathrm{~N}_{4}$ film, and Si window are removed by $\mathrm{HF}$ solution, inductively coupled plasma etching, and $\mathrm{KOH}$ solution, respectively.

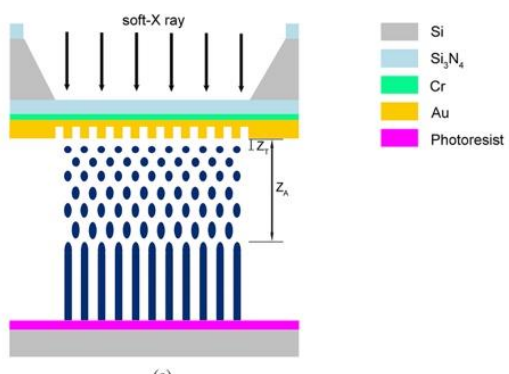

(a)

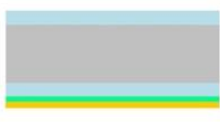

(b)

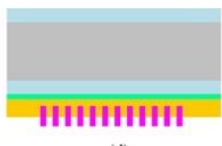

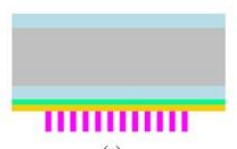

(c)

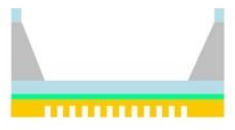

Fig. 2. (a) The scheme of the achromatic Talbot lithography. (b)-(e) The process to fabricate the Talbot grating. (b) Evaporate $\mathrm{Cr}(5 \mathrm{~nm})$ and $\mathrm{Au}$ $(10 \mathrm{~nm})$ film on the $\mathrm{Si}_{3} \mathrm{~N}_{4} / \mathrm{Si}_{2} / \mathrm{Si}_{3} \mathrm{~N}_{4}$ substrate. (c) Exposure the nanostructures of the Talbot grating by e-beam lithography. (d) Electroplate $\mathrm{Au}$ film $(100 \mathrm{~nm})$ as light blocking layer. (e) Remove the photoresist and etch the $\mathrm{Si}$ and $\mathrm{Si}_{3} \mathrm{~N}_{4}$ film on the back side.

\section{Simulations and experimental results}

Before we fabricate color filters using this ATL method, reflection spectra of color filters with different periods were simulated by the finite-difference time-domain (FDTD) method with the Lumercial FDTD Solutions software (Lumerical Solutions, Inc.) The complex dielectric constants (n, k) used in simulations are from Palik's handbook [23]. Perfect matched layer (PML) boundary conditions are used in z directions, symmetric or anti-symmetric boundary conditions are set in $\mathrm{x}$ and $\mathrm{y}$ directions to simplify the simulation. The light source is normal incident plane wave with the wavelength range from $400 \mathrm{~nm}$ to $750 \mathrm{~nm}$. Fig. 3a illustrates the reflection spectra of color filters with P ranging from $30 \mathrm{~nm}$ to $240 \mathrm{~nm}$ with a step of $10 \mathrm{~nm}$. The height of HSQ pillars and the thickness of Ag films are designed to be $40 \mathrm{~nm}$ and $20 \mathrm{~nm}$, respectively. The wavelength of valley of the reflection spectra presents a red-shift when the period increases, and they can almost cover the full visible region. Fig. 3b shows CIE1931 chromaticity diagrams overlaid with points corresponding to the simulated reflection spectra colors of color filters. The color changes from yellow, magenta to cyan along with the increase of the period. The color in the CIE1931 chromaticity diagram covers almost CMYK subtractive color model area, so that it has great potentials to be applied in printing process. 


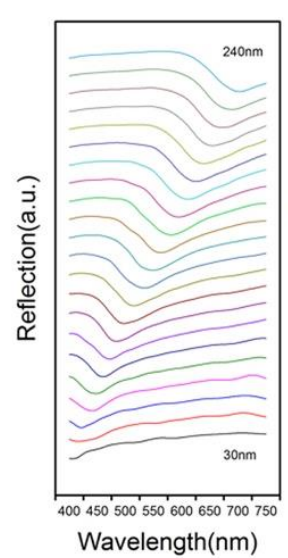

(a)

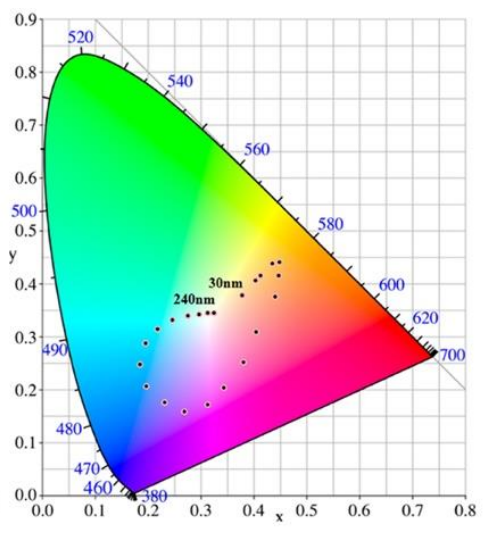

(b)

Fig. 3. (a) Reflection spectra of color filters with P ranging from $30 \mathrm{~nm}$ to $240 \mathrm{~nm}$ in a step of $10 \mathrm{~nm}$. (b) CIE1931 chromaticity diagrams overlaid with points corresponding to the simulated reflection spectra.
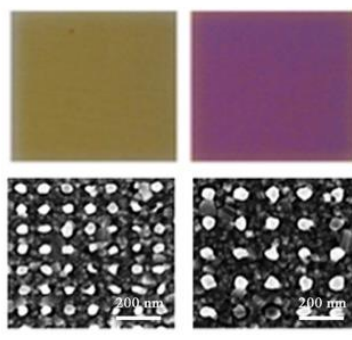

(a)

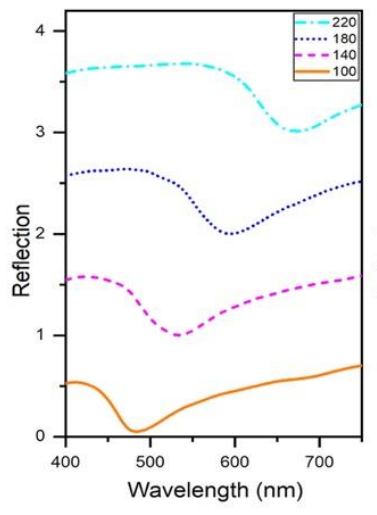

(b)
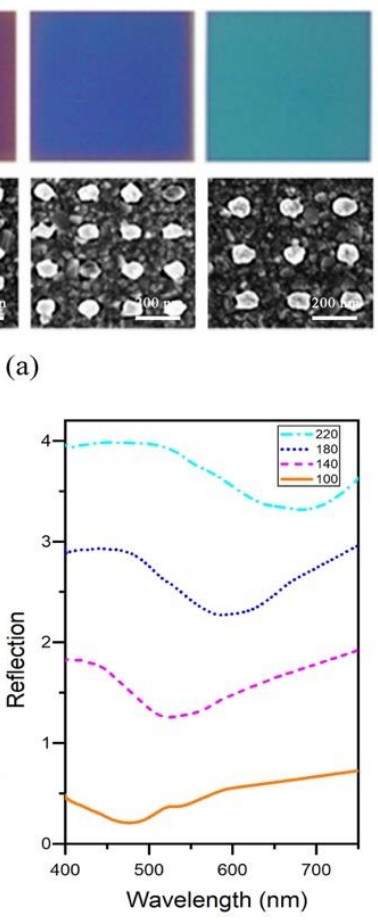

(c)
Fig. 4. (a) The optical micrographs and the SEM images of periodic nanostructures with $\mathrm{P}=100 \mathrm{~nm}, 140 \mathrm{~nm}, 180 \mathrm{~nm}$ and $220 \mathrm{~nm}$. (b) The simulated reflection spectra of periodic nanostructures with $\mathrm{P}=100 \mathrm{~nm}$, $140 \mathrm{~nm}, 180 \mathrm{~nm}$ and $220 \mathrm{~nm}$. (c) The measured reflection spectra of periodic nanostructures with $\mathrm{P}=100 \mathrm{~nm}, 140 \mathrm{~nm}, 180 \mathrm{~nm}$ and $220 \mathrm{~nm}$ obtained by a system with a $100 \mu \mathrm{m}$-sized light spot, under a normal incidence unpolarized white light illumination. For clarity, curves presenting the results of $140 \mathrm{~nm}, 180 \mathrm{~nm}$ and $220 \mathrm{~nm}$ in Figs. 4 (b) and (c) are moved up 100\% in turn.
To validate the simulation results, we first fabricated smallarea color filters by using EBL system in Fig. 4. Fig. 4a shows the optical micrographs and SEM images of color filters by using EBL, the periods of these filtersare $100 \mathrm{~nm}, 140 \mathrm{~nm}, 180 \mathrm{~nm}$ and $220 \mathrm{~nm}$. Figs. $4 \mathrm{~b}$ and c show the simulated and measured reflection spectra individually. The experiment results are in goodagreement with the simulation results in color observation and spectra. Colors have great purity and contrast. Due to the circular shape of the nanostructure, these color filters also have the advantage of polarization independence as revealed in our previous work [13].

Based on above experiments and simulations, two achromatic Talbot gratings and related color filters are fabricated as shown in Fig. 5. Figs. 5a and b show the SEM images of the achromatic Talbot grating with the period of $280 \mathrm{~nm}$, and the corresponding reflection color filter with the period of $200 \mathrm{~nm}$, respectively. Fig. 5c shows the optical micrographs of full area of the reflection color filter with a size of about $0.72 \times 0.72 \mathrm{~mm}^{2}$ by single exposure of only 20 seconds. This is almost 100 times faster than the EBL with the same area and resolution, which is the key factor to reach the throughput of fabrication with high resolution microstructures. Another yellow sample (the grating period is $140 \mathrm{~nm}$ and the related filter period is $100 \mathrm{~nm}$ ) is also fabricated as shown in Figs 5d, e and f to prove the repeatability of this method. Both color filters display the consistency of colors with the simulations and small area experiment results., and their measured reflection spectra presented in Fig. 5g also show agreements with these results. Although further improvement, e.g., overlapping, of the ATL process proposed here is needed, the results in Fig. 5 indicate the potential for wide industrial applications in the fabrication of plasmonic color filter with high resolution and high throughout by the ATL method.

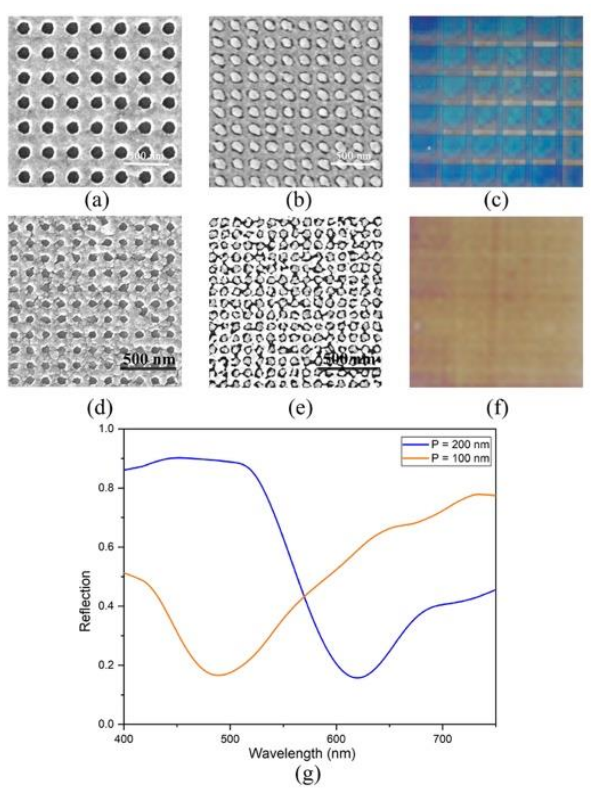

Fig. 5. SEM images of the achromatic Talbot grating with the period of $280 \mathrm{~nm}(\mathrm{a})$, the reflection color filter with the period of $200 \mathrm{~nm}$ fabricated by ATL (b), and its corresponding optical micrograph (c). (df) show the case for the Talbot grating with the period of $140 \mathrm{~nm}$ and the corresponding color filter with the period of $100 \mathrm{~nm}$. (g) Measured reflection spectra of the color filters. 


\section{Conclusions}

In this paper, we propose a novel method to design and fabricate plasmonic reflection color filters with the use of achromatic Talbot lithography. Firstly, we design and simulate various of reflection spectra of color filters with different periods, and make small area color filters by EBL. And then, corresponding achromatic Talbot gratings are fabricated. Finally, by using ATL, we successfully fabricate reflection color filters with a maximum size of about 0.72 x $0.72 \mathrm{~mm}^{2}$ with a time of only 20 seconds and make a series of characterizations. These results demonstrate the possibility of large-scale fabrication of plasmonic color filter with high resolution and high throughout by the ATL method, which has great potential for achieving industry production.

Funding. National Key Research and Development Program of China (Nos. 2017YFA0403403, 2017YFA0403401, 2016YFB0701203), China Scholarship Council (Nos. 201706320249, 201806320375), the Fundamental Research Funds for the Central Universities, Special Program for Applied Research on Super Computation of the NSFC-Guangdong Joint Fund (No. U1501501), The Open Foundation of the State Key Laboratory of Modern Optical Instrumentation (No. MOIKF201701)

Acknowledgment. The authors thank the support of Soft-X Ray Interference Lithography Beamline (BL08U1B) in SSRF for sample preparation and the National Supercomputer Center in Tianjin.

\section{References}

1. A. Boltasseva, T. Søndergaard, T. Nikolajsen, K. Leosson, S. I. Bozhevolnyi, and J. M. Hvam, J. Opt. Soc. Am. B 22, 2027 (2005).

2. S. Landis, P. Brianceau, V. Reboud, N. Chaix, Y. Désieres, and M. Argoud, Microelectron. Eng. 111, 193 (2013).

3. T. W. Ebbesen, H. J. Lezec, H. F. Ghaemi, T. Thio, P. A. Wolff, T. Thio, and P. A.Wolff, Nature 391, 667 (1998).

4. C. Genet and T. W. Ebbesen, Nature 445, 39 (2007).

5. V. S. Volkov, S. I. Bozhevolnyi, E. Devaux, J.-Y. Laluet, and T. W. Ebbesen, Nano Lett. 7, 880 (2007)

6. E. Laux, C. Genet, T. Skauli, and T. W. Ebbesen, Nat. Photonics 2, 161 (2008).

7. B. Zeng, Y. Gao, and F. J. Bartoli, Sci. Rep. 3, 2840 (2013).

8. I. B. Baek and S. Lee, J. Vac. Sci. Technol. B Microelectron. Nanometer Struct. Process. Meas. Phenom. 23, 3120 (2005).

9. Q. Chen, D. Das, D. Chitnis, K. Walls, T. D. Drysdale, S. Collins, and D. R. S. Cumming, Plasmonics 7, 695 (2012).

10. A. S. Roberts, A. Pors, O. Albrektsen, and S. I. Bozhevolnyi, Nano Lett. 14, 783-787 (2014)

11. F. Cheng, J. Gao, L. Stan, D. Rosenmann, D. Czaplewski, and X. Yang, Opt. Express 23, 14552 (2015).

12. X. L. Hu, L. B. Sun, B. Shi, M. Ye, Y. Xu, L. S. Wang, J. Zhao, X. L. Li, Y. Q. Wu, S. M. Yang, R. Z. Tai, H. J. Fecht, J. Z. Jiang, and D. X. Zhang, J. Appl. Phys. 115, (2014).

13. X. L. Hu, L. B. Sun, B. Zeng, L. S. Wang, Z. G. Yu, S. A. Bai, S. A, S. M. Yang, L. X. Zhao, Q. Li, M. Qiu, R. Z. Tai, H.-J. Fecht, J. Z. Jiang, D. X. Zhang, Applied Optics 55, 148 (2016).

14. L. B. Sun, X. L. Hu, B. Zeng, L. S. Wang, S. M. Yang, R. Z. Tai, H. J. Fecht, D. X. Zhang, and J. Z. Jiang, Nanotechnology 26, 305204 (2015).

15. Q. J. Wu, H. Jia, X. L. Hu, L. B. Sun, L. S. Wang, S. M. Yang, R. Z. Tai, H. J. Fecht, L. Q. Wang, D. X. Zhang, and J. Z. Jiang, Nanotechnology 28, 85203 (2017).

16. S. Li, L. Ren, Z. Yang, Z. Zhang, F. Gao, J. Du, and S. Zhang, Microelectron. Eng. 113, 143 (2014).
17. E.-H. Cho, H.-S. Kim, J.-S. Sohn, C.-Y. Moon, N.-C. Park, and Y.-P. Park, Opt. Express 18, 27712 (2010).

18. N. G. Quilis, M. Lequeux, P. Venugopalan, I. Khan, W. Knoll, S. Boujday, M. Lamy de la Chapelle, and J. Dostalek, Nanoscale 10, 10268 (2018).

19. Y. S. Do, J. H. Park, B. Y. Hwang, S.-M. Lee, B.-K. Ju, and K. C. Choi, Adv. Opt. Mater. 1, 109 (2013).

20. H. H. Solak, C. David, J. Gobrecht, L. Wang, and F. Cerrina, Microelectron. Eng. 61-62, 77 (2002).

21. M. Vala and J. Homola, Opt. Express 24, 15656 (2016).

22. L. Sun, X. Hu, Q. Wu, L. Wang, J. Zhao, S. Yang, R. Tai, H.-J. Fecht, D.-X. Zhang, L.-Q. Wang, and J.-Z. Jiang, Opt. Express 24, 19112 (2016).

23. Y. Hua, J. Y. Suh, W. Zhou, M. D. Huntington, and T. W. Odom, Opt. Express 20, 14284 (2012).

24. H. H. Solak, C. Dais, and F. Clube, Opt. Express 19, 10686 (2011).

25. H. H. Solak and Y. Ekinci, J. Vac. Sci. Technol. B Microelectron. Nanom. Struct. 23, 2705 (2005).

26. W. Karim, S. A. Tschupp, M. Oezaslan, T. J. Schmidt, J. Gobrecht, J. A. van Bokhoven, and Y. Ekinci, Nanoscale 7, 7386 (2015).

27. D. Fan, E. Buitrago, S. Yang, W. Karim, Y. Wu, R. Tai, and Y. Ekinci, Microelectron. Eng. 155, 55 (2016).

28. S. Yang, J. Zhao, L. Wang, F. Zhu, C. Xue, H. Liu, H. Sang, Y. Wu, and R. Tai, J. Vac. Sci. Technol. B Nanotechnol. Microelectron. 35, 021601 (2017).

29. E. D. Palik, Handbook of Optical Constants of Solids (Academic, 1985). 
30. H. H. Solak, C. David, J. Gobrecht, L. Wang, and F. Cerrina, "Four-wave EUV interference lithography," Microelectron. Eng. 61-62, 77-82 (2002).

31. M. Vala and J. Homola, "Multiple beam interference lithography: A tool for rapid fabrication of plasmonic arrays of arbitrary shaped nanomotifs," Opt. Express 24, 15656-15665 (2016).

32. L. Sun, X. Hu, Q. Wu, L. Wang, J. Zhao, S. Yang, R. Tai, H.-J. Fecht, D.-X. Zhang, L.-Q. Wang, and J.-Z. Jiang, "High throughput fabrication of largearea plasmonic color filters by soft-X-ray interference lithography," Opt. Express 24, 19112 (2016).

33. Y. Hua, J. Y. Suh, W. Zhou, M. D. Huntington, and T. W. Odom, "Talbot effect beyond the paraxial limit at optical frequencies," Opt. Express 20, 14284-14291 (2012).

34. H. H. Solak, C. Dais, and F. Clube, "Displacement Talbot lithography: a new method for high-resolution patterning of large areas," Opt. Express 19, 10686-10691 (2011).

35. H. H. Solak and Y. Ekinci, "Achromatic spatial frequency multiplication: A method for production of nanometer-scale periodic structures," J. Vac. Sci. Technol. B Microelectron. Nanom. Struct. 23, 2705 (2005).

36. W. Karim, S. A. Tschupp, M. Oezaslan, T. J. Schmidt, J. Gobrecht, J. A. van Bokhoven, and Y. Ekinci, "High-resolution and large-area nanoparticle arrays using EUV interference lithography," Nanoscale 7, 7386-7393 (2015).

37. D. Fan, E. Buitrago, S. Yang, W. Karim, Y. Wu, R. Tai, and Y. Ekinci, "Patterning of nanodot-arrays using EUV achromatic Talbot lithography at the Swiss Light Source and Shanghai Synchrotron Radiation Facility," Microelectron. Eng. 155, 55-60 (2016).

38. S. Yang, J. Zhao, L. Wang, F. Zhu, C. Xue, H. Liu, H. Sang, Y. Wu, and R. Tai, "Influence of symmetry and duty cycles on the pattern generation in achromatic Talbot lithography," J. Vac. Sci. Technol. B Nanotechnol. Microelectron. 35, 021601 (2017).

39. E. D. Palik, Handbook of Optical Constants of Solids (Academic, 1985). 